\title{
Likert-Rating Consensus for SRS Documentation
}

\author{
${ }^{1}$ K.S.N Prasad, ${ }^{2}$ M.V.Vijaya Saradhi, ${ }^{* 3}$ M Rudra Kumar \\ ${ }^{1}$ Professor, Dept. of CSE, Sasi Institute of Technology and Engineering, Tadepalligudem, A.P, India \\ kallisnprasad@gmail.com \\ ${ }^{2}$ Professor, Dept. of CSE, ACE Engineering College, Ghatkesar, Hyderabad, India \\ meduri.vsd@gmail.com \\ ${ }^{* 3}$ Professor, Dept. of CSE, GPCET, Kurnool, A.P, India \\ drrudrakumarcse@gpcet.ac.in
}

Received: $25^{\text {th }}$ July 2021, Accepted: $13^{\text {th }}$ September 2021, Published: $30^{\text {th }}$ October 2021

\begin{abstract}
Developing a successful application system has a distinct set of factors contributing to successful development. One of the key aspects that support quality system development is the SRS (software requirements specifications). While managing the SRS vests in the hands of the project coordination team, there is a need to involve various stakeholders integral to the project environment to get the SRS document right. Many of the earlier studies have presented significant solutions for SRS document management. In this manuscript, focusing on the consensus part of the various stakeholders involved in the document processing, the emphasis is on applying Likert Rating scale model-based regression analysis for consensus. The model presented is a quite simple and domicile approach that can be applied over any set of existing SRS techniques. The experimental case scenario assessment for the project indicates the model as a potential system to improve the overall process outcome in the SRS quality for the projects. Considering such factors, the study's model can be seen as a pragmatic solution to assess and improve consensus among the project stakeholders towards an SRS document.
\end{abstract}

Keywords: Likert-Rating, Software Requirement Specifications (SRS), Likert Scale, Information Technology, Global Software Development (GSD)

\section{Introduction}

Information Systems have become an integral part of business operations efficiency practices. With the increasing trends of SaaS models and cloud-managed enterprise solutions, the cost of managing the information systems for the organizations is evolving into a different paradigm. For instance, there are common framework CRM systems being developed by some IT (Information Technology) product offering companies, which can be customized by the organizations depending on their business operational flow [1].

Also, the rising number of tech-start-up companies worldwide signifies the increasing dependency on technologybased applications to offer customers services. The implicit element of all the developments planned around the software applications refers to the intensity essential in developing the right application systems.

In the other dimension, there are numerous case scenarios wherein reputable businesses have invested millions of dollars in developing information systems. The organizations have failed significantly in realizing the desired outcome from the enterprise applications. Some of the popular ERP failures are the Nike supply chain system, McDonald's, and other organizations. At the same time, there are numerous reasons researched as the critical factor for the failure of the projects. One of the key challenges is about the initial step of not getting the "Software Requirement Specifications" (SRS) defined in non-pragmatic conditions, or there are certain uncertain or ambiguous details that were not effectively accounted for [2]. 
Many of the earlier studies have focused on improving the conditions wherein the SRS is detailed. Over the period, the IEEE standards are incorporated into the SRS definition, which forms the crux for project management. Getting SRS right before the project development execution is profoundly important to mitigate the risks of failure and reduce the challenges of scope deviation impacting the projects [3], [4].

Many academic research studies and industrial practices have evolved over a period in the SRS domain. Despite many techniques and frameworks imperative in the domain, the subject of SRS is still focused on the improvisation of techniques, tools, and practices to ensure a more structured and precise range of inputs on the scope expected from the project [5].

\section{Significance of Software Specifications Requirement}

SRS holds critical importance in the process of software development. The specifications could be attributed to various elements like the business idea, functional flow, performance expectations, process integration, and many other critical factors that are integral to handling software development [1].

The crux in the software requirements planning is documenting the elements like the Key Deliverables expected from the system, the use-case scenarios as to a distinct set of stakeholders who shall be using the application system, business process integration, etc. If such inputs are not assessed effectively by the business analysts, the rest of the project management practices in the system could go wrong [3].

As discussed in the earlier subsection, there are many case scenarios wherein the enterprise applications developed for the organizations spending millions of dollars was ineffective for the organizations, and the implementations were discarded [2], [6]. The other critical reason to ensure the SRS are managed effectively is about the foundation form of SRS for the complete project. Once certain inputs are received as the key performance indicators of the system, the project management team has to focus on the estimations of technologies to be used, skill set requirement of the developers, timeline and effort estimations for completing the project [3], [7].

However, considering the fact about the involvement of various stakeholders integral to the project, if the project communication is not effective, there are possible chances of mismatch in the expectations from the system for the project sponsors and the detailed plans on which the project teams are working. Lack of alignment and coherence in the project expectations among the customers leads to critical challenges for all the stakeholders integral to the project. Thus, there is a need for a simple and structured kind of project management practices in managing the specifications and requirements collection for the projects [8], [9].

\section{Product Vs. Project Scenario}

The other critical scenario is the project vs. product scenario in the software requirements specifications. The critical difference in the requirements management is that the project sponsors are external stakeholders (Clients offering the projects). In the product scenario, the development company has the onus right from ideation to implementation and offering services to the customers. In such a scenario, it is of paramount importance for the internal teams to understand the market expectations and how the customers are keen on various insights in the system [3]. And there is a need for understanding the client's business operations or business process flow effectively to execute the project requirements collection in effective ways [4].

For instance, when an insurance client asks the software company to develop an application, the scope of receiving the definitive set of requirements is very high compared to a software technologies company developing a CRM system as an offering to the customers in the Insurance industry. Right from the magnitude of requirements to be customized to focusing on the key deliverables integral to the project scenario, at every level, the project specifications requirements change, and it can be a significant impact on the project development plans [2], [5].

Thus, there is a need for more emphatic ways to tackle the tactical aspect of aligning all the stakeholders integral to the project into the project specification's agreeability as to what is expected. More often, the system of developing 
a blueprint or the prototype models is seen as the possible structure to mitigate the risks of the projects going wrong, wherein the teams working in the project can be highly resourceful in completing the project as desired [7].

In this manuscript, the objective focuses on the SRS from the statistical point of view and developing a framework wherein a more definitive quantification of the SRS defined for a project is feasible. The emphasis in this project is on the quantification rating of the software specification requirements. Thus, the impact factor is about developing a comprehensive structure that can help improve the accuracy of the SRS systems.

The different sections of this report discuss the related work about the SRS frameworks, tools, and techniques proposed in the earlier studies, followed by the proposed model's conceptual framework, the process flow discussed for the proposed SRS pattern, and the simulated experimental analysis of the model.

\section{Related Work}

In [6], the researchers have discussed the prevailing trends of GSD (Global Software Development) and how the organizations must focus on the contemporary trends of collecting the software requirements specification effectively. The model proposed in the study is about developing a structured specification and rotating the document among the various stakeholder locations. Using the fundamental principle of the role-play among the university academic training, the model is assessed over the management of the specification for an eCommerce application system. Once the complete scenario and scope for the work are attained, the model shall be freeze, and the development process can be initiated.

In [8], a literature review is carried out on the existing set of practices in the SR's functioning, detailing how many of the earlier studies have focused on managing the system development cycle. Ideating on the importance of getting things right in the initial stages and having clarity on what is expected from the domain can help. The study signifies the importance of having the correct assessment of the scope, specifications, and requirements, which will help the project team members assess what set of development plans can suit the timeline and cost estimations integral to managing the project environment. A review of the study is resourceful in understanding the paradigm of getting the first things first to manage the services.

The authors of the study [10] discuss how the studies can focus on the project management life cycle like the linear model of project system development life cycle or focusing on the system development conditions using the waterfall model. The study elementarily discusses the techniques or the patterns in general used for the requirements and specifications collection. Detailing the various steps involved in the process, the study provides insights into the aspects integral to collecting the software requirements specification from the stakeholders.

In [11], the study's authors have focused on software requirements specifications reading to understand the defects, if any, and towards procedural practices for addressing the defects. In principle, the authors' efforts focus on the problems leading to defects using appropriate techniques. Focusing on the gaps in the prevailing trends of SRS, the authors have proposed a combined-reading technique model to identify defects in the requirements. It is advocated in the study about using the proposed combined-reading model to reduce the erroneous development in the domain.

Requirements in the software application could be classified into functional and non-functional. The organizational teams need to have the right information on the key outcomes expected from the project. In [11], the study discusses the techniques integral to managing the tuning and formally working on the specification of a conceptual model integral to the requirements' documentation. The study covers the importance of classification for both functional and non-functional elements like the performance parameters, which holds critical importance in the long-term success factors for the project. Information practices integral to the system of specifications collection discussed in the model can support developing a sustainable outcome.

In [12], the study discusses the assessment models to understand how the individual scope requirements defined be assessed for significant improvements in the model. The study argues that the behavior models constructed in line with the system scenarios enable managing the requirements elicitation and verification, code generation, and early 
analysis of the software requirements. The study evaluates various models that can be used to trigger scenario languages for tackling the problem in modeling a large range of software systems. The models discussed in the study refer to a system wherein a small portion of a prototype for the expected system is generated using simple languages, which can help in mitigating the risks or unclear requirements in the system and improve the overall process outcome.

A unique systematic approach in understanding the requirement variability modeling in the case of business applications is discussed in the study [13]. Feature Model (FM) is an effective model adapted for managing the system's variability using the use case model. The study observes that the variability studies in the projects usually do not cover holistic requirements at the modeling levels. There is a need to focus on the significant elements integral to the process. Thus, in the study, the authors have presented bio-inspired requirements variability analysis models that can improve the analysis by focusing on three meta-levels like the business domain, specification requirements, and applications family. The contextual analysis from the models refers to the conditions wherein the requirements are analyzed for a custom fit, contextual fit for the domain, and the overall feasibility of implementation.

In [14], the study focuses on the issues of requirements implementation management in software development. Based on the studies' information, requirement management is one of the critical challenges faced in the implementation scenario. While the facets of requirement management issues like inaccurate or insufficient data, scope creep in the implementation phase, or ineffective skill can cause major concerns in terms of affecting the outcome expected from the project. Thus, there is a need for more emphatic management practices, which requires the projects' scope to be managed more effectively.

In summary of the related work, it is evident that there are certainly best practices and techniques integral to managing the SRS in the software industry. Still, in terms of getting the consensus from all the key stakeholders before the project's execution, there is a need to double-check the kind of confirmation practices that can yield good results in completing the project.

\section{Conceptual Framework:}

The conceptual framework proposed in this manuscript is a statistical analysis model, which can be resourceful for the organizations in developing a reconfirmation to the techniques adopted in the SRS framework patterns. Many of the existing frameworks or the techniques discussed in the studies refer to a potential documentation process; the proposed model is profoundly about accepting various stakeholders integral to the model [4].

The Conceptual framework for the model focuses on the archetypes that can have more stakeholder engagement and apply the model with the statistical approach of "Likert Scale," which can help improve the overall sustainable ways of requirement collection. The elementary reason for proposing the Likert scale model is to focus on the stakeholders' perception and the qualitative analysis. In general, the requirements for SRS are assessed in general lines of SMART (Specific, Measurable, Actionable, Realistic, and Time-bound). But more often, the desired outcome from the specifications could be different from what is portrayed in the documentation. Thus, focusing on the perceptions in terms of re-evaluating what is good in the system and how it can be resourceful for the organizations are critical measures to be considered by the project teams [5].

The model proposed in this study is a checklist pattern that can be applied after developing the SRS documentation for a project charter. The emphasis in the model is about collecting the consensus of the different stakeholders and agrees on the kind of specifications discussed in the model, which can be integral to the systematic development of the project [15].

\section{Likert Scale}

The Likert Scale refers to a rating scale model more often used in the questionnaire and survey for gauging how the respondents feel about a question posed in the survey. Named after a social scientist Rensis Likert, the psychometric model is more often used to ask the respondents about opinions or feelings in the survey research, having certain 
options in the range for a question. Respondents can provide a negative, positive, or neutral response for a statement, reflecting the respondents' possible likelihood, importance, or agreement [4], [16].

Likert Scale presumes an attitude's intensity as linear, with underlying conditions of presuming it as a task that can be measured. The model allows quantitative data to be collected and to be analyzed in much easier contexts. However, there are possible chances of compromised attitude measurement in the instances of bias to social desirability. Construction of the Likert scale instrument for a survey is generally with the options range of 5 to 7 point Scale constituting a middle neutral option [16].

In some of the early-stage research over the integrity of the Likert Scale, researchers have assessed the model for possibilities of left-side bias, wherein the respondents might be inclined to pick the options to range on the left side. However, some studies have focused on similar lines and have advocated the usage of vertical Likert Scales as respondents for the optional range to be chosen in an unbiased manner. Thus, it is imperative that in the application of the Likert Scale, there is significance to the structuring of the Likert Scale to avoid any bias and sloppy answering from the respondents [17].

In Table 1, the Likert Scale Layout refers to the possible levels of bias conditions in the structure (horizontal or vertical) model that could be adapted for the structure and how it can support the overall quality of data collected from the model [18].

Table 1: Likert Scale Layout refers to the possible levels

\begin{tabular}{|l|l|l|l|}
\cline { 3 - 4 } \multicolumn{2}{c|}{} & \multicolumn{2}{|l|}{ Bias Level } \\
\cline { 3 - 4 } \multicolumn{2}{l|}{} & Lower & Higher \\
\hline \multirow{3}{*}{ Likert Scale Layout } & \multirow{2}{*}{ Horizontal } & Negative Attitude Left & Positive Attitude Left \\
\cline { 3 - 4 } & \multirow{2}{*}{ Vositive Attitude Right } & Negative Attitude Right \\
\cline { 3 - 4 } & & $\begin{array}{l}\text { Negative Attitude Top } \\
\text { Positive Attitude Bottom }\end{array}$ & Positive Attitude Top \\
\hline
\end{tabular}

\section{Measurable Scale}

- Agreement: Strongly agree to disagree strongly

- Frequency: Often to never

- Quality: Very good to very bad

- Likelihood: Definitely to never

- Importance: Very important to unimportant

The attributes discussed in the measurable Scale are some of the common patterns followed in the implementation of the Likert Scale. For the proposed Likert Scale-based SRS consensus model, the model can be more significant and can offer the right kind of insights. More apt measurable scales perceived for the SRS requirements are quality, importance, and agreement [19]. 


\section{Measurable Metrics}

The metrics are integral to the proposed SRS requirement consensus analysis structure, as mentioned in Table 2.

Table 2: The metrics integral to the proposed SRS requirement consensus analysis structure

\begin{tabular}{|c|c|c|c|c|c|}
\hline $\begin{array}{l}1 . \\
\text { a) } \\
\text { b) } \\
\text { c) }\end{array}$ & $\begin{array}{l}\text { Accuracy: } \\
\text { Needs } \\
\text { Comparison } \\
\text { Construction }\end{array}$ & & $\begin{array}{l}\text { 2. UNAMBIGUOUS: } \\
\text { a) Uniqueness } \\
\text { b) Language Snag } \\
\text { c) Errors } \\
\text { d) Formal Notation } \\
\text { e) Interpretation }\end{array}$ & $\begin{array}{l}\text { 3. COMPLETE: } \\
\text { a) Requirements } \\
\text { b) Definitions } \\
\text { c) Labeling/Referencing } \\
\text { d) Undetermined } \\
\text { e) Constraints }\end{array}$ & $\begin{array}{l}\text { 4.CONSISTENCY: } \\
\text { Internal consistency } \\
\text { a) Expression } \\
\text { b) Divergence } \\
\text { c) Vocabulary } \\
\text { External consistency } \\
\text { a) Changeability } \\
\text { b) Compatibility }\end{array}$ \\
\hline 5 & $\begin{array}{l}\text { RANKED } \\
\text { TANCE AND } \\
\text { LITY: } \\
\text { sification } \\
\text { istency } \\
\text { tability }\end{array}$ & $\begin{array}{r}\text { FOR } \\
\text { OR }\end{array}$ & $\begin{array}{l}\text { 6. VERIFIABLE: } \\
\text { a) Ambiguity } \\
\text { b) Vagueness } \\
\text { c) Immeasurability } \\
\text { d) Testability }\end{array}$ & $\begin{array}{l}\text { 7. MODIFIABLE: } \\
\text { a) Organization } \\
\text { b) Redundancy } \\
\text { c) Intermixing }\end{array}$ & $\begin{array}{l}\text { 8. TRACEABLE: } \\
\text { a) Backward } \\
\text { traceability } \\
\text { b) Forward } \\
\text { traceability }\end{array}$ \\
\hline
\end{tabular}

The proposed analysis is based on the eight-key metrics considered integral to the model, wherein some of the contextual and implicit factors integral to the project environment are considered. The proposed structure is about choosing the sub-elements required for the project scenario and seeking ratings from all the stakeholders integral to the project, which can be assessed for statistical analysis.

\section{Correlation Values and Regression Analysis}

The correlation analysis refers to the sample correlation coefficient wherein the Pearson Product Moment Correlation Coefficient, wherein the sample correlation coefficient is depicted by notion $r$, which usually ranges between -1 and +1 . The readings signify the strength of the linear association among the variables chosen for the comparison.

The studies in the domain emphasize the scope of a non-linear association possibility among two distinct variables, wherein the computation of a correlation coefficient does not identify the conditions. Hence, the data is assessed effectively for more intrinsic analysis of the correlation [20].

$$
r=\frac{\sum\left(x_{i}-\bar{x}\right)\left(y_{i}-\bar{y}\right)}{\sqrt{\sum\left(x_{i}-\bar{x}\right)^{2} \sum\left(y_{i}-\bar{y}\right)^{2}}} \ldots(\operatorname{Eq} 1)
$$

The $r$ correlation coefficient, $x_{i}$ values of the $\mathrm{x}$-variable in a sample, $\bar{x}$ mean of the values of the $\mathrm{x}$-variable, $y_{i}$ values of the $y$-variable in a sample, $\bar{y}$ mean of the values of the $y$-variable.

The eq 1 refers to the P-value correlation coefficient analysis, followed in the statistical analysis estimations.

\section{Methodology}

\section{Process Flow of proposed model Likert-SRS}

The process flow for the proposed manuscript is as follows

Step-1 
The SRS document is developed by the project team based on the scope, key deliverables, validations, and process flow provided by the project sponsors (customer/ clients/internal departments). The project SRS document is developed in line with the IEEE framework for the project requirements standard guidelines.

Project specification documentation is completed in terms of the following
a) Draft Project configuration
b) Project Dictionary
c) Project Charter

\section{Step-2}

Develop a survey instrument with a measurable scale as detailed below and metrics applicable to the earlier section's measurable metrics.

- Agreement: Strongly agree to disagree strongly

- Quality: Very good to very bad

- Likelihood: Definitely to never

- Importance: Very important to unimportant [21]

\section{Step-3}

The draft document shall be provided to the respective stakeholder's integral to the project

Project stakeholders considered in this manuscript

- Project Owners - (Client / Project sponsors / Customers)

- Business Analyst - (Internal BA and Client-end BA)

- System Analyst - (Internal System Analyst)

- Project Manager

- Project Development Team (Random Member selection)

- One External Consultant

- Prospective / Potential Customer (If possible)

The project stakeholders considered respondents to the model is flexible and the teams or individuals deemed necessary for the model can be considered for the survey analysis

\section{Step-4}

The responses collected from the survey shall be assessed for statistical analysis of correlation values and the hypothesis.

\section{Step-5}

If the hypothesis values are encouraging, freeze the SRS document and continue with the project implementation.

P-value derived from the analysis should satisfy the null hypothesis chosen for the review.

\{the null hypothesis chosen generally for the proposed model is "Are all the requirements expected from the stakeholders are addressed in the SRS document";

Else 
Revisit the document for the necessary changes in the critically low scoring pattern, revise the scope initiatives and re-execute the survey

The statistical analysis for the respondent analysis for the proposed model is executed in line with the statistical and mathematical correlation formulae discussed in [22].

\{Assessment model in the following experimental analysis of the model, in terms of mathematical execution in the spreadsheets, is conducted using the pre-defined formulae functions mentioned in the spreadsheets. \}

\section{Step-6}

Project Implementation

\section{Results}

\section{Case Scenario}

For the experimental study of the proposed model, the case scenario considered in the domain is the association of a Web Development company from India, offering the CMS (Content Management Services) website for its customer from the Overseas Educational Consulting domain.

The service offering organization has worked on the RFP (requirements for the project) and accordingly developed the holistic SRS document assessed in the current model. To maintain the organizations' discretion, the data analysis is referred to in conceptual representation as Rn (R1-R9) for various stakeholders in the assessment. In Table 3, 15 questions in the survey process for various metrics integral to the measurable metrics, and accordingly, the study has surveyed lines with the procedural steps.

Table 3: Questions in the survey process for various metrics integral to the measurable metrics

\begin{tabular}{|c|c|c|c|c|c|c|c|c|c|c|c|c|c|c|c|c|}
\hline 1 & & Overall Scope & $F R$ & NFR & \begin{tabular}{|c|} 
Technolog \\
$y$
\end{tabular} & $\begin{array}{c}\text { Validation } \\
s\end{array}$ & KRAs & $\begin{array}{c}\text { Configurati } \\
\text { on }\end{array}$ & $\begin{array}{l}\text { Interop } \\
\text { erability }\end{array}$ & $\begin{array}{c}\text { Consiste } \\
\text { ncy }\end{array}$ & \begin{tabular}{|c|} 
Scope \\
Languag \\
$e$
\end{tabular} & $\begin{array}{c}\text { Peforma } \\
\text { nce }\end{array}$ & $\begin{array}{c}\text { Measurab } \\
\text { ility }\end{array}$ & $\begin{array}{c}\text { Traceabi } \\
\text { lity }\end{array}$ & $\begin{array}{c}\text { Labelin } \\
g\end{array}$ & $\begin{array}{c}\text { Constra } \\
\text { ints }\end{array}$ \\
\hline 2 & Overall Scope & 1 & & & & & & & & & & & & & & \\
\hline 3 & FR & -0.1768 & 1 & & & & & & & & & & & & & \\
\hline 4 & NFR & 0.8165 & -0.2887 & 1.0000 & & & & & & & & & & & & \\
\hline 5 & Technology & -0.1622 & -0.1434 & 0.3311 & 1.0000 & & & & & & & & & & & \\
\hline 6 & Validations & -0.2236 & 0.7906 & -0.1826 & -0.0907 & 1.0000 & & & & & & & & & & \\
\hline 7 & KRAS & 0.2113 & -0.5976 & 0.2415 & -0.1714 & -0.6614 & 1.0000 & & & & & & & & & \\
\hline 8 & Configuration & -0.1768 & 0.0500 & 0.1443 & 0.5907 & 0.1739 & \begin{tabular}{|l|}
-0.1016 \\
\end{tabular} & 1.0000 & & & & & & & & \\
\hline 9 & Interoperability & 0.5276 & -0.5330 & 0.4924 & -0.1528 & -0.4382 & 0.7199 & -0.0906 & 1.0000 & & & & & & & \\
\hline 10 & Consistency & 0.2321 & -0.0657 & 0.2653 & -0.2786 & 0.2699 & 0.1569 & -0.5055 & 0.4549 & 1.0000 & & & & & & \\
\hline 11 & Scope Language & -0.2357 & 0.3333 & -0.0962 & -0.0191 & 0.2635 & \begin{tabular}{|l|}
-0.1992 \\
\end{tabular} & 0.0167 & -0.3376 & -0.0875 & 1.0000 & & & & & \\
\hline 12 & Peformance & -0.0767 & -0.4339 & 0.2505 & 0.2862 & -0.0686 & 0.3954 & 0.2224 & 0.6648 & 0.5198 & -0.0904 & 1.0000 & & & & \\
\hline 13 & Measurability & -0.2157 & -0.0762 & -0.3522 & -0.2974 & -0.0482 & 0.2916 & 0.0762 & -0.1057 & -0.1602 & -0.5592 & -0.2398 & 1.0000 & & & \\
\hline 14 & Traceability & 0.0000 & 0.6187 & -0.3062 & -0.3447 & 0.2236 & -0.4860 & -0.2828 & -0.6030 & -0.3946 & 0.5303 & -0.8245 & -0.2157 & 1.0000 & & \\
\hline 15 & Labeling & -0.0442 & 0.1250 & -0.0722 & -0.2222 & 0.3162 & 0.0598 & 0.4375 & -0.1866 & \begin{tabular}{|l|}
-0.1805 \\
\end{tabular} & -0.2083 & -0.2169 & 0.7625 & -0.1105 & 1.0000 & \\
\hline 16 & Constraints & -0.5076 & 0.5245 & -0.4463 & -0.0253 & 0.5413 & \begin{tabular}{|l|}
-0.2442 \\
\end{tabular} & 0.5356 & \begin{tabular}{|l|}
-0.1648 \\
\end{tabular} & \begin{tabular}{|l|}
-0.2248 \\
\end{tabular} & 0.4233 & 0.1857 & -0.0842 & 0.1367 & 0.2002 & 1.0000 \\
\hline
\end{tabular}

Table 4 refers to the distinct set of correlations among the various metrics at various levels, which will help the project manager decide which aspects of the parameters considered have higher correlation and the gaps integral to the conditions. In some instances, the negative correlation could be the outcome of the lack of scope for the measure as there are chances of non-fitment of assessment. For instance, configuration and technology have a high correlation, whereas configuration and labeling have a negative correlation, which refers to the possible nonmeasurable circumstance [23].

\section{Table 4: Set of correlations among various metrics at various levels}




\begin{tabular}{|c|c|c|c|c|c|c|c|c|}
\hline SUMMARY OUTPUT & & & & & & & & \\
\hline \multicolumn{9}{|c|}{ Regression Statistics } \\
\hline Multiple R & 0.956866431 & & & & & & & \\
\hline R Square & 0.915593366 & & & & & & & \\
\hline Adjusted R Square & 0.831186732 & & & & & & & \\
\hline Standard Error & 0.290528199 & & & & & & & \\
\hline Observations & 9 & & & & & & & \\
\hline \multicolumn{9}{|l|}{ ANOVA } \\
\hline & $d f$ & SS & $M S$ & $F$ & Significance $F$ & & & \\
\hline Regression & 4 & 3.662373463 & 0.915593 & 10.84740999 & 0.020170733 & & & \\
\hline Residual & 4 & 0.337626537 & 0.084407 & & & & & \\
\hline \multirow[t]{2}{*}{ Total } & 8 & 4 & & & & & & \\
\hline & Coefficients & Standard Error & t Stat & P-value & Lower $95 \%$ & Upper $95 \%$ & Lower $95.0 \%$ & Upper $95.0 \%$ \\
\hline Intercept & 1.184336587 & 0.76775421 & 1.542599 & 0.197794704 & -0.947290833 & 3.315964007 & -0.947290833 & 3.315964007 \\
\hline FR & 0.207926609 & 0.172942979 & 1.202284 & 0.295558166 & -0.27224008 & 0.688093298 & -0.27224008 & 0.688093298 \\
\hline NFR & 0.818781634 & 0.130432146 & 6.277453 & 0.003287741 & 0.456643941 & 1.180919327 & 0.456643941 & 1.180919327 \\
\hline Technology & -0.234002169 & 0.075034396 & -3.1186 & 0.035574771 & -0.44233105 & -0.025673289 & -0.44233105 & -0.025673289 \\
\hline Validations & -0.141585322 & 0.106419768 & -1.33044 & 0.254154446 & -0.437053966 & 0.153883323 & -0.437053966 & 0.153883323 \\
\hline
\end{tabular}

The regression analysis estimated five of the key integral metrics assessed for the overall rating by the stakeholders, the p-value information detailed in the study as a critical input to help in the more effective assessment. The kind of results generated from the model indicates how the $p$-values at a higher value of $p>0.05$ to accept the null hypothesis or to reject the hypothesis [24]. As detailed in the process flow section, the null hypothesis in the model is about referring to the positive correlation between the overall scope and the respective metric. In the instance of any metric having a negative p-value condition, the scope of revision in the document for the respective metric attribute can be considered by the project management team at their discretion.

\section{Conclusion}

Information systems development is evolving rapidly, and one of the critical factors that lead to the successful development of the information system is the effective management of SRS (Software Requirement Specifications). It is of paramount importance that the developers have well-defined inputs in place on what is expected from the system, and SRS plays a pivot role in such definition. While there are many models and conceptual frameworks approved by the Industry bodies for working on SRS documents, this manuscript proposes a systematic approach to work on improving consensus among the stakeholders integral to the SRS document. The Likert scale rating-based regression analysis model proposed in this study refers to the potential system wherein all stakeholders' consensus can be assessed for a null-hypothesis scenario. The experimental pattern analysis discussed in this manuscript refers to the possible implementation levels for the model, which can help in overall sustainable development.

\section{References}

[1] https://worldwidescience.org/topicpages/s/software+requirement+specification.html

[2] Gupta AK, Dearman A. A framework for software requirement ambiguity avoidance. International Journal of Electrical \& Computer Engineering (2088-8708). 2019 Dec 15;9.

[3] Kirner TG, Abib JC. Inspection of software requirements specification documents: A pilot study. In Proceedings of the 15th annual international conference on Computer documentation 1997 Oct 1 (pp. 161171).

[4] Putra FP, Enda D. Model design for grammatical error identification in software requirements specification using statistics and rule-based techniques. In Journal of Physics: Conference Series 2020 Feb (Vol. 1450, p. 012071). 
[5] Nilsson S, Lindahl M. A literature review to understand the requirements specification's role when developing integrated product service offerings. In8th CIRP IPSS Conference, Product-Service Systems across Life Cycle, Bergamo, Italy, June 20-21, 20162016 (Vol. 47, pp. 150-155). Elsevier.

[6] Ali N, Lai R. A method of software requirements specification and validation for global software development. Requirements Engineering. 2017 Jun 1;22(2):191-214.

[7] C.Arun, S.Karthick, G Sivan Muthu Krishnan, and Soumitro Dutta. A Tool for Analyzing Software Requirements Document Quality, International Journal of Recent Technology and Engineering (IJRTE) ISSN: 2277-3878, Volume-8 Issue-2S4, July 2019, pp. 274-279.

[8] Dr. Brijesh Kumar Bhardwaj, Dr. Sharubh Pal, A Critical Review On Software Requirements Specification: Quality Perspective, International Journal of Engineering Science, International Journal of Technical Innovation in Modern Engineering \& Science (IJTIMES), Impact Factor: 5.22 (SJIF-2017), e-ISSN: 24552585 Volume 4, Issue 09, September-2018.

[9] Alshazly AA, Elfatatry AM, Abougabal MS. Detecting defects in software requirements specification. Alexandria Engineering Journal. 2014 Sep 1;53(3):513-527.

[10] Pandey D, Pandey V. Requirement Engineering: An Approach to Quality Software Development. Journal of Global Research in Computer Science. 2012 Oct 10;3(9):31-3.

[11] Yeh RT, Zave P. Specifying software requirements. Proceedings of the IEEE. 1980 Sep;68(9):1077-85.

[12] Ali A. Early software behaviour modeling methods: a review. Journal of software engineering \& intelligent systemsissn 2518-8739, 30 April 2020, Volume 5, Issue 1, pp. 76-82.

[13] Abdel-Ghani E, Ghoul S. Bio-inspired Requirements Variability Modeling with Use Case. International Journal of Software Engineering \& Applications (IJSEA). 2019 Mar 21;10(2).

[14] Muhammad Yaseen, Rashid Naseem, Zahid Ali, Ghufran Ullahidentification Of Challenges Duringrequirements Implementation In Global Software Development: A Systematic Literature Review, 30th April 2019, Volume 4, Issue 1, JSEIS, pp. 23-40.

[15] Vegendla A, Duc AN, Gao S, Sindre G. A systematic mapping study on requirements engineering in software ecosystems. Journal of Information Technology Research (JITR). 2018 Jan 1;11(1):49-69.

[16] Khin Hayman Oo, Azlin Nordin, Amelia Ritahani Ismail, Suriani Sulaiman, An Analysis of Ambiguity Detection Techniques for Software Requirements Specification (SRS), Copyright @ 2018Authors.This is an open-access article distributed under the Creative Commons Attribution License, which permits unrestricted use, distribution, and reproduction in any medium provided the original work is properly cited. International Journal of Engineering \& Technology, 7(2.29)(2018) 501-505.

[17] Owuor, Charles Ochieng. Implications of using Likert data in multiple regression analysis. Diss. University of British Columbia, 2001.

[18] Russell CJ, Bobko P. Moderated regression analysis and Likert scales: Too coarse for comfort. Journal of applied psychology. 1992 Jun;77(3):336.

[19] Gail M. Sullivan, Anthony R. Artino Analyzing and Interpreting Data from Likert-type ScalesJ Grad Med Educ. 2013 Dec; 5(4): 541-542. DOI: 10.4300/JGME-5-4-18 PMCID: PMC3886444 PMID: 24454995.

[20] Zou KH, Tuncali K, Silverman SG. Correlation and simple linear regression. Radiology. 2003;227(3):61722.

[21] Yusoff R, Mohd Janor R. Generation of an interval metric scale to measure attitude. Sage Open. 2014 Jan 6;4(1):2158244013516768.

[22] Hazra A, Gogtay N. Biostatistics series module 6: correlation and linear regression. Indian journal of dermatology. 2016 Nov;61(6):593.

[23] Boone HN, Boone DA. Analyzing Likert data. Journal of extension. 2012 Apr 2;50(2):1-5.

[24] Bishop PA, Herron RL. Use and misuse of the Likert item responses and other ordinal measures. International journal of exercise science. 2015;8(3):297. 